\section{CONTEXTUALIZANDO E DISCUTINDO AS ATIVIDADES LÚDICAS EM CIÊNCIAS NO ENSINO FUNDAMENTAL}

\author{
Contextualizing and discussing play activities in sciences in middle school
}

Contextualizando y discutindo las actividades lúdicas en ciencias en la enseñanza fundamental

\section{Resumo}

O objetivo da pesquisa foi verificar as diferentes formas compreendidas por atividades lúdicas presentes nos livros didáticos e currículos e os papéis que ocupam nesses documentos demonstrando a importância atribuída a essas atividades, e de que forma estampam diferentes documentos oficiais. Analisou-se os Parâmetros Curriculares Nacionais de Ciências, os Conteúdos Básicos Curriculares do Estado de Minas Gerais, as Diretrizes Curriculares Nacionais e o Programa Nacional do Livro Didático. Além desses, verificou-se também a presença das atividades lúdicas em duas coleções didáticas de Ciências. Constata-se que as atividades lúdicas se fazem presente em quase todos os currículos e são consideradas por eles importantes no processo de aprendizagem, sendo compreendidas pelos currículos como ações que podem atuar como agente, paciente ou meio no processo de ensino e aprendizagem. As atividades lúdicas se fazem presentes nos livros didáticos, porém muitas vezes são consideradas como complemento sendo apresentadas apenas no manual do professor como sugestões de atividades. Observa-se a existência de recontextualização dos livros didáticos sobre as orientações curriculares.

Palavras-Chave: Atividades lúdicas; Currículos; Ensino Fundamental; Recontextualização.

\section{Abstract}

The aim of the research was to verify the different forms included in the activities of textbooks and curricula and the roles they occupy in these documents in order to demonstrate the importance attributed to these activities, in which they form different official documents. The documents analyzed were: Parâmetros Curriculares Nacionais de Ciências, Conteúdos Básicos Curriculares do Estado de Minas Gerais, Diretrizes Curriculares Nacionais and Programa Nacional do Livro Didático. Besides these, some didactic collections of Sciences were also analyzed. It has been found that play activities are present in almost all curricula and are considered by them to be important in the learning process. The play activities are understood by the curricula as actions that can act as agent, patient or means in the process of teaching and learning. There are play activities in textbooks, however they are often considered as complements and are presented only in the teacher's manual as suggestions for activities. We observed the existence of recontextualization of the textbooks on the curricular guidelines.

Keywords: Play Activities; Curriculum; Middle School; Recontextualization.

\section{Resumen}

El objetivo de la investigación fue verificar las diferentes formas comprendidas por actividades lúdicas presentes en los libros didácticos y currículos, así como los papeles que ocupan en esos documentos, con el objetivo de demostrar la importancia atribuida a esas actividades, y de qué forma estampan diferentes documentos oficiales. Los documentos analizados fueron los Parámetros Curriculares Nacionales de Ciencias, los Contenidos Básicos Curriculares del Estado de Minas Gerais, las Directrices Curriculares Nacionales y el Programa Nacional del Libro Didáctico. También se analizaron dos colecciones didácticas de Ciencias. Se verificó que las actividades lúdicas se hacen presentes en casi todos los currículos y son consideradas por ellos importantes en el proceso de aprendizaje. Las actividades lúdicas son entendidas por los currículos como acciones que pueden actuar como agente, paciente o medio en el proceso de enseñanza y aprendizaje. Existen actividades lúdicas en los libros didácticos, pero muchas veces se consideran como complemento, siendo presentadas sólo en el manual del profesor como sugerencias de actividades. Observamos la existencia de recontextualización de los libros didácticos sobre las orientaciones curriculares.

Palabras clave: Actividades lúdicas; Los currículos; Enseñanza primaria; Recontextualización.
AUTORAS:

BÁRBARA ELISA SANTOS
CARVALHO LUZ

ORCID 0000-0002-4312-4017

${ }^{1}$ Professora da

Educação Básica

MÔNICA DA SILVA

GALLON ${ }^{2}$

ORCID 0000-0003-0793-2372

${ }^{2}$ Professora da Rede

Municipal

SILVANIA SOUSA DO

NASCIMENTO 3

ORCID 0000-0002-5189-1961

3 Universidade Federal

de Minas Gerais

(UFMG)

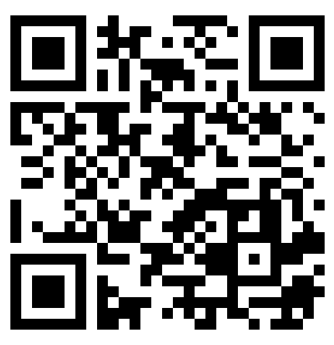

Para citar este artigo:

LUZ, B. E. S. C.; GALLON, M. S.; NASCIMENTO, S. S. Contextualizando e discutindo as atividades lúdicas em ciências no ensino fundamental.

Revista Eletrônica Ludus Scientiae, Foz do Iguaçu, v. 01, n. 02, p. 14-30, ago./dez. 2017. 


\section{INTRODUÇÃO}

O A investigação aqui apresentada é resultante de uma pesquisa de Mestrado realizada em um Programa de Pós-Graduação em Educação sobre as atividades lúdicas nas orientações curriculares e nos livros didáticos de Ciências do Ensino Fundamental II (LUZ, 2014). Entendemos que a compreensão do significado do lúdico na educação, sobretudo no ensino de Ciências é indispensável para o seu aprimoramento com vistas a enriquecer suas possibilidades pedagógicas refletindo em uma melhor compreensão de mundo e dos seus fenômenos, um dos objetivos da educação em Ciências.

Acreditamos na importância do elemento lúdico na educação em Ciências como estratégia contra um dos grandes problemas enfrentados pelos professores em sala da aula: o desinteresse dos estudantes pelos conteúdos escolares trabalhados. Dentre as razões, o aumento do número de vagas nas escolas ao longo das últimas décadas promoveu uma mudança no perfil do público recebido por essas instituições e de suas motivações, conforme sinalizado por Macedo e Passos (2005). Para essas autoras, na escola seletiva de antigamente, ingressavam somente aqueles que preenchiam determinados requisitos. O desejo de aprender e o prazer em realizar as atividades escolares não eram problemas, e sim, pressupostos dos esforços das crianças e dos pais para que elas permanecessem e progredissem na escola. Essa transformação do público atendido tornou a escola um ambiente heterogêneo, em que as motivações se tornaram variadas e, em sua maioria, externas e condicionais. Além disso, "normalmente não é que não estejam motivados, que não se movimentem em absoluto; o que ocorre é que se mobilizam para coisas diferentes e em direções diferentes daquelas que pretendem seus professores" (POZO; CRESPO, 2009, p. 41)

Atualmente, constata-se que uma escola dita não lúdica não é atraente para os alunos, pois eles não a entendem como algo que lhes será bom em um futuro remoto, aplicada às profissões que eles nem sabem o que significam (MACEDO; PASSOS, 2005). Para além das questões relacionadas ao interesse, concordamos com Carleto (2003) em relação à importância do lúdico no processo de aprendizagem, o que fomenta a necessidade de pesquisas nessa área. A autora afirma que por meio das atividades lúdicas, a criança estabelece diferentes relações que subsidiam o processo da construção do conhecimento, uma vez que pressupõe uma ação provocando cooperação e articulação de pontos de vista estimulando assim a representação e a operatividade.

Dispostas a investigar a referida temática, julgamos ser necessário analisar as orientações curriculares que definem os conteúdos que devem ser trabalhados nas salas de aulas de Ciências, o Programa Nacional do Livro Didático que conduz os autores e editoras na produção das coleções didáticas em si. Dessa forma, selecionamos como fonte para a composição do corpus dessa investigação: as Diretrizes Curriculares Nacionais da Educação Básica, os Parâmetros Curriculares Nacionais, o Programa Nacional do Livro Didático, os Conteúdos Básicos Curriculares do Estado de Minas Gerais e duas coleções didáticas de Ciências do Ensino Fundamental. Para entendermos as seleções de assuntos e as modificações pelos quais esses conteúdos passam até chegar à sala de aula, baseamo-nos na teoria do dispositivo pedagógico de Bernstein (1996) que analisa como determinado conhecimento é adaptado para o ambiente de aprendizagem escolar.

A pesquisa possibilitou a compreensão de como as atividades lúdicas perpassam o programa do governo federal que orienta a produção dos livros didáticos e pelos currículos norteadores de conteúdos de Ciências de abrangência nacional e estadual. Identificamos a partir disso, as similaridades e as discordâncias entre os diferentes discursos curriculares e caracterizamos como acontece a recontextualização pelas editoras e autores das coleções didáticas a partir do discurso oficial em relação às atividades lúdicas. Assim, foi possível construir uma problematização acerca do tema e indicar possibilidades para pesquisas futuras. 


\section{REFERENCIAL TEÓRICO}

\section{Atividades lúdicas e as possibilidades na Educação em Ciências}

Percorrer os verbetes dos dicionários na busca do significado do lúdico é uma experiência interessante, de acordo com Marcellino (1997). Entretanto, conforme afirma o autor, é também uma atividade pouco esclarecedora, pois mais de uma dezena de substantivos são registrados, nos dicionários da língua portuguesa em relação a tal termo. Existem estudos clássicos em relação ao lúdico em seus diferentes aspectos. Huizinga (1971) estudou o termo lúdico sob as características histórico-culturais, Benjamim (1984) deu foco em suas discussões às características histórico-sociais e Brougère (1998) analisou os aspectos sociais dos jogos. No âmbito nacional, existem trabalhos importantes que nos ajudam a elucidar essa definição como, por exemplo, as pesquisas de Volpato (2002), Macedo (2003) e Macedo e Passos (2005) sobre os quais discorremos brevemente a seguir.

Em sua obra clássica Homo ludens, Huizinga (1971) sinalizou sobre a dificuldade de definição do termo ao afirmar que o lúdico está ligado a finalidades além do campo dos interesses materiais ou da satisfação individual, sendo possível encontrar características lúdicas em todas as atividades humanas. Posteriormente, Gilles Brougère (1998) em suas discussões relacionando o lúdico à educação, afirma que, antes do século XIX o jogo jamais havia sido associado à prática educativa. Somente após uma ruptura desencadeada pelo pensamento romântico, o jogo começou a ser pensando enquanto uma ferramenta educativa, encontrando ainda hoje resistência por parte de alguns profissionais da educação. Em uma pesquisa de revisão bibliográfica sobre o jogo e o brinquedo no campo da Educação, realizada por Volpato (2002), é exposto que, principalmente nas sociedades ocidentais, as características do brincar e jogar mudaram radicalmente. A constatação dessa autora pode ser exemplificada com um fato recorrente da sociedade atual: os filhos de uma geração que tinham como hábito ampla variedade de brincadeiras na rua, nascem já imersos em tecnologias que lhes roubam toda atenção e diminuem as possibilidades de socializações pessoais.

Apesar de muitos autores relacionarem lúdico ao jogo, observa-se a ausência de consenso na literatura sobre o significado do termo atividade lúdica. Entretanto, devemos estar atentos a esse ponto, pois de acordo com Brougère (1998), ao trabalharmos com o vocábulo jogo não podemos agir com se dispuséssemos de um termo claro e transparente, e sim, estar cientes de que estamos lidando com uma noção aberta, polissêmica e, às vezes, ambígua. Cientes da amplitude do termo, mas também da necessidade de delimitação de um significado que viabilize a investigação aqui apresentada, utilizamos como base para definição do referido vocábulo os estudos de Macedo e Passos (2005) apresentados no livro Os jogos e o lúdico na aprendizagem escolar. As autoras apresentam, com base nos estudos de Macedo (2003), cinco indicadores que permitem inferir a presença do lúdico em atividades escolares: prazer funcional, desafio $e$ surpresa, possibilidades, dimensão simbólica e expressão construtiva.

Ao relacionar as possibilidades do lúdico na Educação em Ciências, destaca-se a pesquisa realizada por Moura (1993) na qual ele denominou tal relação como dimensão lúdica. Essa dimensão se refere ao potencial lúdico existente na interação do indivíduo com os objetos e os fenômenos que existem no mundo físico, natural e tecnológico que o cerca. O autor diferencia duas características inerentes à Educação em Ciências: o impulso sensível relacionado à manipulação, experimentação e interação do ser com os fenômenos físicos, naturais e tecnológicos e o impulso formal que consiste no universo das elaborações conceituais relativas àqueles fenômenos.

Para Moura (1993) um dos problemas da Educação em Ciências no Brasil é que ocorre uma valorização do impulso formal, sendo os valores afetivos e estéticos deixados de lado enquanto a conjugação de valores sensíveis e racionais tem a capacidade de promover o impulso lúdico e melhorar os resultados no processo de aprendizagem dos alunos. 
Outra importante contribuição para esse cenário foi feita por Kishimoto (1999) ao afirmar que a dimensão educativa pode surgir quando as situações lúdicas são criadas com intencionalidade de estimular certos tipos de aprendizagens. Para a autora, não adianta desenvolver um formalismo em sala de aula se este não constitui um problema para o estudante, já que não se espera superação em suas concepções alternativas se ele não estiver motivado em construir e questionar hipóteses (KISHIMOTO, 1999). Destaca-se ainda os apontamentos de Testa Braz da Silva, Mettrau e Barreto (2007), para os quais as concepções prévias relacionadas a conceitos científicos são pontos de partida no processo da construção de novos conceitos e a motivação é considerada o elemento propulsor desse processo.

Para a realização da presente pesquisa, faz-se necessária uma definição própria de atividade lúdica. Consideramos para identificação dessas atividades nos livros didáticos os indicadores propostos por Macedo e Passos (2005), que possibilitam a inferência da ludicidade em atividades escolares. Nossa delimitação de atividade lúdica também se aproxima das afirmações de Friedman (1996) que considera as mesmas como o brinquedo, a brincadeira e o jogo. Levando em consideração que, para realizar a presente pesquisa, teríamos que identificar as atividades lúdicas em coleções de livros didáticos, elaboramos, com base nos estudos anteriormente elencados, uma lista com os possíveis modelos de atividades lúdicas a serem encontradas nessa categoria de material. As atividades por nós consideradas lúdicas nos livros foram: jogos, teatros ou encenações, histórias em quadrinhos, charges, discussões sobre filmes, cartas enigmáticas, palavras codificadas, palavras cruzadas, diagramas, atividades relacionadas aos sentidos, atividades envolvendo linguagens literárias, criações como esculturas/desenhos e gincanas.

\section{A relação entre as orientações curriculares e os livros didáticos à luz das ideias de Bernstein}

Currículo pode ser entendido como orientações aos conteúdos a serem ensinados em uma instituição de ensino, experiências escolares que os estudantes devem vivenciar propostas pedagógicas, formas de avaliação entre outros. Silva (2001) afirma que as discussões sobre essa temática incorporam com maior ou menor ênfase, debates sobre os conhecimentos escolares, procedimentos pedagógicos e relações sociais que são estabelecidas em um ambiente educativo. Tomaz Tadeu da Silva, grande referência em currículo no Brasil (SILVA, 2001), afirma que o currículo é concebido como elemento discursivo da política educacional. Podemos evidenciar nas pesquisas na área educacional a existência de teorias críticas e pós-críticas do currículo. As teorias críticas acrescentaram à ideia tradicional de currículo apenas conteudista e metodológico, as relações de poder e as ideologias, enquanto as teorias pós-críticas incorporam, além disso, um discurso curricular que produz identidades culturais e sociais (SILVA, 2001).

A teoria do dispositivo pedagógico proposta por Bernstein (1996) pode ser entendida como a forma pela qual determinado conhecimento é adaptado para o ambiente de aprendizagem escolar. Os textos, sejam eles oficiais ou não, passam por fragmentações ao circularem pelo corpo social da educação sendo alguns desses fragmentos mais valorizados que outros. Analisando as políticas curriculares, Lopes (2005) sistematiza o dispositivo pedagógico de Bernstein em dois campos: o campo recontextualizador por parte do governo (aqui entendidos na figura das orientações curriculares) e o campo recontextualizador pedagógico (nesse contexto, os livros didáticos). O caminho do conteúdo desde sua produção na respectiva área de conhecimento até chegar ao aluno na escola passa pelo discurso pedagógico oficial (DPO). Nesse discurso, o governo seleciona o que julga importante e, em seguida, passa pelo discurso pedagógico recontextualizador (DPR) no qual os autores e editoras selecionam, a partir do DPO, o que é consideram necessário vigorar nas coleções didáticas, constituindo assim o DPR. 
Um exemplo de pesquisa que buscou investigar a recontextualização em conformidade com os aspectos acima mencionados foi realizada por Calado e Neves (2012), na Universidade de Lisboa. As autoras evidenciam o influente papel dos livros didáticos em sala de aula, uma vez que professores não têm o hábito de consultar os documentos curriculares. Dessa forma, esses materiais exercem a função de principais mediadores curriculares e comportam em sua estrutura um conjunto de informações formais para o contexto de transmissão/aquisição, atuando de maneira determinante sobre os conhecimentos que são discutidos em sala de aula e como são ensinados. Os resultados dessa investigação apontam um elevado grau de recontextualização das mensagens dos documentos oficiais.

\section{METODOLOGIA}

\section{A escolha do corpus de análise}

Para a escolha do corpus da pesquisa, foi realizada uma investigação inicial sobre os currículos oficiais existentes e uma observação superficial sobre cada um. A partir disso, os documentos selecionados para a análise foram: as Diretrizes Curriculares Nacionais da Educação Básica - DCNEB (BRASIL, 2013), os Parâmetros Curriculares Nacionais - PCN (BRASIL, 1998) o Programa Nacional do Livro Didático - PNLD (BRASIL, 2014), os Conteúdos Básicos Curriculares do Estado de Minas Gerais - CBC (MINAS GERAIS, 2006) e duas coleções didáticas de Ciências do Ensino Fundamental.

As DCNEB são um conjunto de normas, ancoradas na Lei de Diretrizes e Bases da Educação que orientam o planejamento curricular das escolas e dos sistemas de ensino de Educação Básica no Brasil. Tem como função orientar a organização, a articulação, o desenvolvimento e a avaliação das propostas pedagógicas de todas as redes de ensino brasileiras e não designa os conteúdos a serem trabalhados nas escolas e sim, traça um panorama apresentando vários aspectos que devem ser considerados no planejamento execução do processo educacional (BRASIL, 2013).

Os PCN orientam os professores quanto ao significado do conhecimento escolar quando contextualizado e à interdisciplinaridade, incentivando o raciocínio e a capacidade de aprender. Visam o respeito às especificidades culturais, regionais e políticas observando a necessidade da construção de referências nacionais comuns ao processo educativo no país (BRASIL, 1998).

O Programa Nacional do Livro Didático, lançado em 1985, tem por objetivo subsidiar o trabalho pedagógico dos professores garantindo a distribuição de coleções de livros didáticos para as diferentes áreas do conhecimento, nos diferentes níveis da Educação Básica. O Ministério da Educação, por meio de um edital, convoca e avalia obras inscritas pelas editoras de todo o país e divulga a cada triênio um guia de livros didáticos composto por resenhas das coleções consideradas aprovadas e elegíveis para a adoção nas escolas públicas (BRASIL, 2014).

No estado de Minas Gerais, a Secretaria Educação norteia a escolha dos conteúdos escolares por meio de um documento chamado Conteúdo Básico Curricular, publicado em 2006 (MINAS GERAIS, 2006). Tal documento foi produzido em parceria com professores da Rede Estadual e abarcam os aspectos fundamentais pertinentes a cada disciplina, assim como indicam habilidades e competências a serem desenvolvidas. Após avaliação dos conteúdos, alguns recortes foram realizados com o objetivo de viabilizar a análise. O quadro 1 apresenta os recortes de análise por nós realizados.

Quadro 1: Currículos analisados e os respectivos recortes.

\begin{tabular}{|l|l|}
\hline \multicolumn{1}{|c|}{ Currículo/ Ano de publicação/ Abrangência } & \multicolumn{1}{c|}{ Recorte de análise } \\
\hline Diretrizes Curriculares Nacionais/ 2013/ Nacional & $\begin{array}{l}\text { Diretrizes Nacionais para o Ensino } \\
\text { Fundamental }\end{array}$ \\
\hline
\end{tabular}




\begin{tabular}{|l|l|}
\hline Parâmetros Curriculares Nacionais/ 1998/ Nacional & $\begin{array}{l}\text { Capítulo de Introdução e capítulo de } \\
\text { Ciências }\end{array}$ \\
\hline Programa Nacional do Livro Didático / 2014/ Nacional & Edital \\
\hline $\begin{array}{l}\text { Conteúdos Básicos Curriculares do Estado de Minas Gerais/ } \\
\text { 2006/ Estadual }\end{array}$ & $\begin{array}{l}\text { Capítulo referente à disciplina de } \\
\text { Ciências }\end{array}$ \\
\hline
\end{tabular}

Fonte: As autoras.

A escolha das coleções para compor a análise foi feita a partir da leitura do Guia do PNLD de 2014 (BRASIL, 2014), que apresenta uma resenha de todas as coleções aprovadas. De acordo com esse guia, apenas quatro das vinte coleções apresentavam categorias de atividades que buscávamos e, dessa forma, optamos pela escolha de duas delas para uma leitura criteriosa: "Vontade de Saber Ciências", e "Ciências, Natureza e Cotidiano" ambas da editora FTD. Verificamos, portanto, quatro livros de cada coleção (6ํㅜ , $7^{\circ}, 8^{\circ}$ e e $9^{\circ}$ anos) totalizando oito obras ${ }^{1}$.

\section{Delineamento metodológico}

Para a análise dos currículos selecionados e das coleções didáticas utilizamos a Análise de Conteúdo que, de acordo com Bardin (2009), consiste em um conjunto de técnicas de análise das comunicações, sejam elas quantitativas ou não que objetivam o tratamento da informação contida nas mensagens. Para a autora, a análise de conteúdo deve seguir três etapas: a pré-análise dos dados, a exploração do material e o tratamento dos resultados obtidos e interpretação (BARDIN, 2009).

Na pré-análise, fase de organização do material, fez-se a seleção dos documentos a compor a base de dados e, em seguida, uma leitura flutuante dos mesmos para uma aproximação prévia à análise propriamente dita. A exploração do material, que consiste essencialmente em operações de codificação permitindo que o analista atinja uma representação do conteúdo passível de esclarecer as suas características, foi realizada pela separação dos dados em unidades de registro e unidades de contexto.

Por unidade de registro, entendemos, conforme Bardin (2009), a unidade que permite a investigação do papel que se atribui a algo. Nesse caso, utilizamos como unidade de registro o personagem atividades lúdicas. Seria necessário, então, localizar essa expressão nos documentos. Porém, de forma a ampliar as chances de selecionar trechos dos currículos que abordassem o lúdico que porventura não usassem a expressão "atividade lúdica", listamos dezenove palavras e termos de busca que poderiam remeter de alguma forma à referida expressão e, dessa forma, buscamos por todas elas nos currículos, a saber: lúdico, lúdica, divertido, prazeroso, brincadeira, entretenimento, recreação, jogo, competição, oficina, encenação, teatro, dramatização, história em quadrinhos, gibi, cartum, caça palavras, palavra cruzada e cruzadinha.

Já por unidade de contexto, entendemos o segmento da mensagem cujas dimensões (superiores às unidades de registro) facilitam a significação da compreensão da unidade de registro, ou seja, é unidade de compreensão (BARDIN, 2009). Na presente análise, adotamos para tal, o parágrafo nos quais a unidade de registro foi encontrada.

Na terceira e última fase denominada por Bardin (2009) como tratamento e interpretação dos resultados, optamos pela realização da análise categorial temática que consiste em operações de fragmentação do texto em categorias segundo reagrupamentos analógicos. Nesse momento da análise, utilizamos traços metodológicos² tais como os empregados por Bertelli (2010),

\footnotetext{
${ }^{1}$ Identificação das coleções analisadas:

COLEÇÃO 1. Título: Vontade de saber Ciências; Código; 1ª edição de 2012; Autores: Leonardo Pereira de Godoy e Marcela Yaemi Ogo; Editora FTD.

COLEÇÃO 2. Título: Ciências, natureza e cotidiano; 2ae edição de 2012; Autores: Carlos Aparecido Kantor, José Trivellato Júnior, Júlio Cezar Foschini Lisboa, Marcelo Tadeu Motokane e Sílvia Luzia F. Trivellato; Editora FTD.

${ }^{2}$ Os traços metodológicos registrados por Bertelli (2010) foram definidos pelo grupo de pesquisa o qual as autoras do artigo fazem parte.
} 
também baseada da análise de conteúdo Bardiniana, trouxe a realização de perguntas às unidades selecionadas com objetivo de identificação de imagens e papéis presentes do texto analisado. As perguntas realizadas ao texto foram: O que é a atividade lúdica? E Qual é o papel da atividade lúdica na educação? As respostas dessas indagações nos remeteriam respectivamente à imagem e ao papel desempenhado por elas. O quadro 2, a título de exemplificação dessa etapa metodológica, apresenta um trecho da análise por nós realizada. Nele, observa-se como as respostas feitas aos documentos foram respondidas e como as imagens e os papéis das atividades lúdicas presentes nesses emergiram.

Quadro 2: Exemplo da análise dos dados.

\begin{tabular}{|c|c|c|c|c|}
\hline \multicolumn{5}{|c|}{ Parâmetro Curricular Nacional de Ciências - PCN (Ciências) } \\
\hline $\begin{array}{l}\text { Palavra e } \\
\text { Localização }\end{array}$ & $\begin{array}{lll}\begin{array}{l}\text { Unidade } \\
\text { (Parágrafo) }\end{array} & \text { de } & \text { Contexto } \\
\end{array}$ & $\begin{array}{l}\begin{array}{l}\text { Sub } \quad \text { unidade } \\
\text { contexto }\end{array} \text { (Frases) } \\
\text { de }\end{array}$ & $\begin{array}{l}\text { O que é a } \\
\text { atividade } \\
\text { lúdica? } \\
\text { (Imagem) }\end{array}$ & $\begin{array}{l}\text { Qual é o } \\
\text { papel da } \\
\text { atividade } \\
\text { lúdica na } \\
\text { educação? } \\
\text { (Papel) }\end{array}$ \\
\hline \multirow[t]{3}{*}{ Jogo $27 / 7$} & $\begin{array}{l}\text { Assim, o estudo das Ciências } \\
\text { Naturais de forma exclusivamente } \\
\text { livresca, sem interação direta com } \\
\text { os fenômenos naturais ou } \\
\text { tecnológicos, deixa enorme lacuna } \\
\text { na formação dos estudantes. } \\
\text { Sonega as diferentes interações } \\
\text { que podem ter com seu mundo, } \\
\text { sob orientação do professor. Ao } \\
\text { contrário, diferentes métodos } \\
\text { ativos, com a utilização de } \\
\text { observações, experimentação, } \\
\text { jogos, diferentes fontes textuais } \\
\text { para obter e comparar } \\
\text { informações, por exemplo, } \\
\text { despertam o interesse dos } \\
\text { estudantes pelos conteúdos e } \\
\text { conferem sentidos à natureza e à } \\
\text { ciência que não são possíveis ao se } \\
\text { estudar Ciências Naturais apenas } \\
\text { em um livro. }\end{array}$ & $\begin{array}{l}\text { Assim, o estudo das } \\
\text { Ciências Naturais de forma } \\
\text { exclusivamente livresca, } \\
\text { sem interação direta com os } \\
\text { fenômenos naturais ou } \\
\text { tecnológicos, deixa enorme } \\
\text { lacuna na formação dos } \\
\text { estudantes }\end{array}$ & $\begin{array}{l}\text { Ação causada pela } \\
\text { interação direta } \\
\text { com fenômenos } \\
\text { naturais e } \\
\text { tecnológicos (2) }\end{array}$ & - \\
\hline & & $\begin{array}{l}\text { Sonega } \\
\text { diferentes interações } \\
\text { podem ter com seu mundo, } \\
\text { sob orientação do professor. }\end{array}$ & - & - \\
\hline & & $\begin{array}{l}\text { Ao contrário, } \\
\text { diferentes métodos ativos, } \\
\text { com a utilização de } \\
\text { observações, } \\
\text { experimentação, jogos, } \\
\text { diferentes fontes textuais } \\
\text { para obter e comparar } \\
\text { informações, por exemplo, } \\
\text { despertam o interesse dos } \\
\text { estudantes pelos conteúdos } \\
\text { e conferem sentidos à } \\
\text { natureza eà ciência que não } \\
\text { são possíveis ao se estudar } \\
\text { Ciências Naturais apenas } \\
\text { em um livro. }\end{array}$ & \begin{tabular}{l}
\multicolumn{2}{c}{ Ação } \\
que desperta o \\
interesse dos \\
alunos e confere \\
sentido à natureza \\
da ciência (1) \\
Ação \\
que promove um \\
melhor \\
aprendizado do \\
que somente o \\
livro didático (1)
\end{tabular} & $\begin{array}{lr} & \text { Des } \\
\text { pertar } & \text { o } \\
\text { interesse } & \text { dos } \\
\text { alunos } & \\
& \\
& \\
& \text { Mel } \\
\text { horar a } & \text { a } \\
\text { aprendizagem }\end{array}$ \\
\hline
\end{tabular}

Fonte: As autoras. 
As imagens das atividades lúdicas percebidas com as respostas da primeira pergunta foram prioritariamente ações que podem despenhar três tipos funções no processo de aprendizagem conforme é apresentado no quadro 3: A ação com função de agente, a ação com função de paciente e a ação com função de meio. A imagem da atividade lúdica como agente se refere a essas como uma ação promovedora. A imagem da atividade lúdica como paciente se refere a essas como ação causadora. Já a imagem da atividade lúdica como meio, refere-se a essas como intermediadora. Os papéis das atividades lúdicas percebidos com as respostas da segunda pergunta foram agrupados por semelhanças, a esses agrupamentos demos o nome de temas.

Quadro 3: Classificação das imagens das atividades lúdicas nos currículos.

\begin{tabular}{|ll|c|}
\hline \multicolumn{2}{|c|}{ Imagem } & Características \\
\hline$(1)$ & AGENTE & Ação que promove algo (Promovedora) \\
\hline$(2)$ & PACIENTE & Ação causada por algo (Causadora) \\
\hline$(3)$ & MEIO & Ação que ocorre por meio de algo (Intermediadora) \\
\hline
\end{tabular}

Fonte: As autoras.

A análise das coleções didáticas foi realizada posteriormente a análise dos currículos. Inicialmente foi realizada uma leitura e observação de todo o conteúdo dos livros em busca das atividades lúdicas. Após a identificação dessas e de posse das imagens e dos papéis encontrados nos currículos, realizamos uma classificação dessas atividades. Objetivamos com isso verificar se as imagens e os papéis existentes nos currículos estão presentes nas atividades lúdicas dos livros didáticos ancorados do conceito de recontextualização Bernstein (1996).

\section{RESULTADOS}

Existem nos currículos analisados 64 imagens das atividades lúdicas que as caracterizam como ações que podem apresentar três diferentes funções: agente, paciente e meio. A imagem denominada por nós de agente (imagem 1) é considerada uma ação que promove algo como o prazer ou o entretenimento facilitando o aprendizado de determinado conteúdo. A imagem denominada paciente (imagem 2) é aquela na qual a atividade lúdica é considerada uma ação causada por algo, por exemplo, uma descoberta. São as atividades que fazem parte de um processo a ser realizado com os alunos, tais como, gincanas. Já a imagem meio (imagem 3) está relacionada a atividade lúdica como uma ação que ocorre por intermédio de recursos, jogos ou outros relacionados. A imagem 1 foi a mais recorrente nos currículos analisados, encontrada 41 vezes. As outras imagens apareceram de forma equitativa em menor frequência que a anterior, 10 ocorrências cada uma, ao longo dos documentos.

A partir dessa primeira análise, podemos afirmar que para as DCNEB, as atividades lúdicas se caracterizam prioritariamente por algumas ações que, quando realizadas na escola, conseguem promover algo diferente como, por exemplo, o prazer aos alunos envolvidos e, a partir disso, proporcionar o aprendizado. Entretanto, nos PCN foi observada uma diferença nas imagens atribuídas às atividades lúdicas entre o capítulo de introdução e o capítulo de Ciências. No capítulo de introdução, a imagem 1 é a mais recorrente seguida pela imagem 3 e 2, respectivamente. Já no capítulo de Ciências, a distribuição é equitativa uma vez que as três imagens aparecem praticamente com o mesmo número de recorrências. Assim, podemos inferir que, para os PCN de Ciências, as atividades lúdicas têm as três imagens, porém, o capítulo geral de introdução atribui a essas atividades apenas uma condição de ação capaz de promover algo, enquanto o específico de Ciências confere importância às três imagens com a mesma intensidade. Entre todos os currículos analisados, o PNLD é o que parece reportar maior importância às atividades lúdicas, uma vez que observamos nele o maior número de parágrafos relacionados ao assunto e a imagem mais marcante nesse documento é a número 1. Destaca-se 
a importância concedida a esse tipo de atividades nesse currículo, uma vez que a presença dessas era considerada requisito à aprovação das coleções didáticas pelo PNLD.

Foram verificados na análise 47 papéis das atividades lúdicas, sendo esses agrupados por semelhança. Tal agrupamento resultou em 13 papéis principais conforme é apresentado no quadro 4 .

Quadro 4: Papéis das atividades lúdicas nos currículos.

\begin{tabular}{|c|c|}
\hline & Papel das atividades lúdicas \\
\hline 1 & Oferecer motivação ao aluno, despertar seu interesse pelo ensino e proporcionar-lhe prazer. \\
\hline 2 & $\begin{array}{l}\text { Trabalhar aspectos sociais que são importantes para o desenvolvimento da autonomia, ampliação de } \\
\text { valores e o exercício crítico da cidadania. }\end{array}$ \\
\hline 3 & Provocar um desafio de modo a estimular o aluno a realizar determinadas tarefas por meio de recursos. \\
\hline 4 & Permitir a atualização dos alunos. \\
\hline 5 & Possibilitar o planejamento e a execução de projetos. \\
\hline 6 & Transmitir conteúdos. \\
\hline 7 & Permitir uma maior exploração de linguagens artísticas. \\
\hline 8 & Promover a afetividade e a criatividade. \\
\hline 9 & Proporcionar a interação entre os alunos e entre os alunos e os professores. \\
\hline 10 & Explorar e desenvolver noções de mobilidade, medidas, proporções e relacionados. \\
\hline 11 & Estabelecer conexões entre a realidade cotidiana dos alunos e os conteúdos curriculares. \\
\hline 12 & Possibilitar e facilitar a aprendizagem. \\
\hline 13 & Qualificar a ação pedagógica. \\
\hline
\end{tabular}

Fonte: as autoras.

Alguns papéis estão presentes em mais de um currículo, enquanto outros são exclusivos de algum deles. Essa atribuição diferenciada de papéis às atividades lúdicas por cada um dos currículos é apresentada diagrama 1.

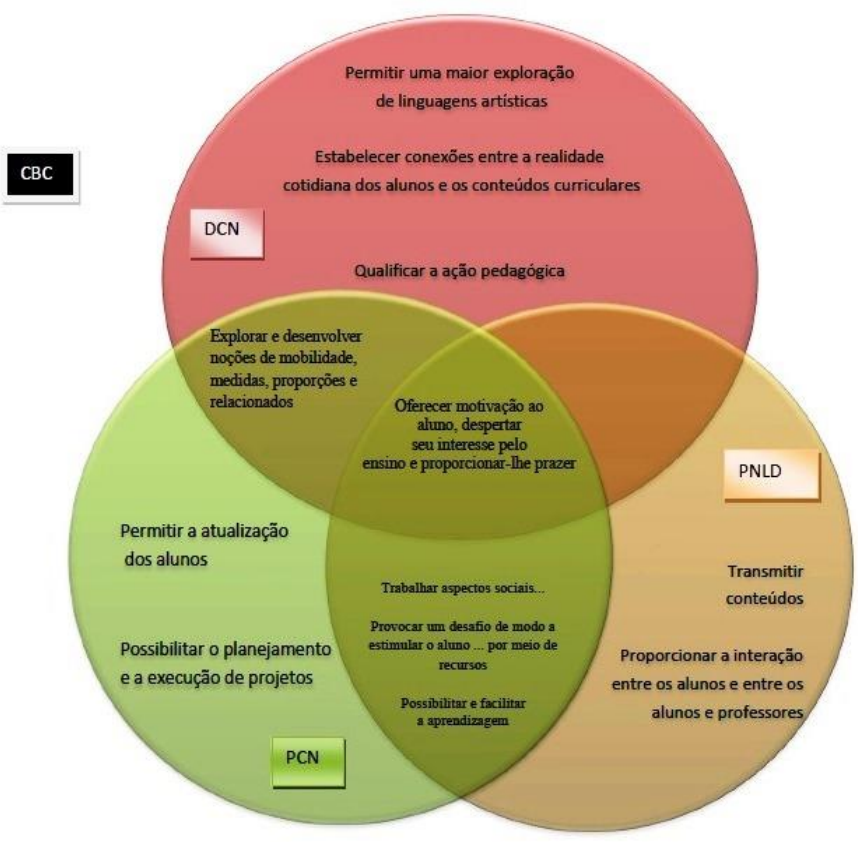

Diagrama 1: Atribuição de papéis às atividades lúdicas pelos currículos analisados. Fonte: As autoras. 
As DCNEB trazem em seu conteúdo, alguns parágrafos nos quais discorrem sobre as atividades lúdicas caracterizando-as como atividades que atuam como agente, uma ação que promove o prazer, o entretenimento ou como fonte para outras emoções/sensações que podem facilitar o aprendizado sobre determinado conteúdo escolar. O referido currículo atribui a essas atividades o papel de motivar o aluno, estabelecer uma relação entre o conteúdo escolar e o cotidiano dos estudantes, explorar linguagens artísticas e também ressalta a importância da qualificação da ação pedagógica na execução dessas práticas. Os $\mathrm{PCN}$, apesar de não apresentarem em seu conteúdo o termo lúdico ou atividades lúdicas, abordam-as indiretamente ao tratar de jogos, teatros, entretenimento e oficinas. Na introdução, tais atividades são mais relacionadas à ações (agente) assim como nas DCNEB. Já no capítulo de Ciências, observamos a presença das três imagens de forma equilibrada.

Os PCN, de forma geral, conferem a essas atividades as funções de atualizar os estudantes, possibilitar a execução de projeto, além de incentivar e motivar os educandos. Não há nada relacionado às atividades lúdicas nos CBC de Ciências de Minas Gerais. Como não foi encontrada nenhuma das palavras buscadas com sentido apropriado, concluímos que as atividades lúdicas não são consideradas importantes no processo de ensino e aprendizagem de Ciências no Ensino Fundamental pelos CBC.

As atividades lúdicas aparecem várias vezes no PNLD 2014 (BRASIL, 2014). Além de serem consideradas como um requisito às coleções, o termo lúdico foi recorrente ao longo do texto, sendo esse entre os analisados, o currículo que mais dedicou espaço a abordagem de tais atividades. Para o PNLD, as atividades lúdicas são prioritariamente agentes ou ações que podem acontecer em um ambiente de aprendizagem, mas o mesmo também reconhece que atividades com essa natureza podem ser pacientes, ocorrendo por intermédio de um processo e também como meio, com o emprego de recursos, como os jogos.

Após a leitura e análise dos oito livros das duas coleções selecionadas, identificamos a presença de 54 atividades lúdicas das quais 48 foram analisadas. Com vistas a organizar a análise, denominamos as coleções escolhidas da seguinte forma: Coleção 1 - Vontade de Saber Ciências (Editora FTD) e Coleção 2 - Ciência, Natureza e Cotidiano (Editora FTD). Constatamos que a Coleção 1 apresenta um número muito maior de atividades lúdicas que a Coleção 2. Além disso, na primeira, essas se encontram concentradas no livro do aluno enquanto na segunda, existem apenas no manual do professor. Além da diferença entre estar no livro do aluno ou no livro do professor, observamos que as atividades são distribuídas em quatro locais diferentes nas obras: em atividades no final de capítulos acompanhadas de perguntas, no meio dos capítulos enquanto o conteúdo é apresentado também acompanhado de perguntas -, como introdução de um capítulo/unidade com questionamentos que promovem uma reflexão inicial acerca de um tema ou como sugestão de atividades a serem estimuladas pelo o professor.

Observamos que na Coleção 1, existem atividades nos quatro locais relatados sendo que a maioria está localizada junto aos demais exercícios contidos ao final de cada capítulo. Geralmente são charges ou histórias em quadrinhos relacionadas ao conteúdo desenvolvido. Já na Coleção 2, em função de todas as atividades lúdicas estarem presentes no manual do professor, são apresentadas como sugestão de atividades, de forma complementar ao conteúdo.

Em relação à distribuição das atividades lúdicas por ano escolar, nas duas coleções elas existem em maior quantidade nos livros do 8a ano. Na Coleção 1, o livro do $7^{\circ}$ ano inclui também um número relevante de atividades lúdicas, seguido pelo $9^{\circ}$ ano e, por fim, com menos atividades, o 60 ano. Já na Coleção 2, a distribuição é mais equilibrada por ano escolar. Quanto ao tipo de atividade, foram detectadas atividades lúdicas como: jogo, teatros, quadrinho, charges, filmes e diagramas, gincanas, atividade que utilizam os sentidos sensoriais entre outras. Na Coleção 1, a maioria das atividades lúdicas localizadas consistiam em histórias em quadrinhos, seguidas por jogos e charges. Já na Coleção 2, identificamos grande número de jogos, seguido por associação de linguagem literária com ciência, criação de esculturas e gincanas. 
Foram averiguados também os assuntos tratados nas referidas atividades. Na Coleção 1 o tema mais recorrente é o corpo humano, seguido por zoologia e física. Já na Coleção 2, os temas mais presentes são a física, o corpo humano e tema livre (atividades nas quais é solicitado que o aluno escolha um capítulo do livro como base para realizá-la).

Após selecionarmos e analisarmos todas as atividades lúdicas presentes nas duas coleções e diferenciar qual o tipo de imagem detectada nos currículos está presente nessas atividades, observamos que, de forma geral, a imagem 1 (atividade lúdica como ação agente) é a que apresenta maior recorrência nas mesmas. Em seguida, verificamos a imagem 2 (atividade lúdica como ação paciente) e a imagem 3 (atividade lúdica como ação meio) com a mesma ocorrência, porém, em menor proporção que a imagem 1. Também buscamos identificar entre os papéis verificados nos currículos, aqueles que estão presentes ou ausentes nas atividades lúdicas dos livros didáticos. Apenas um dos 13 papéis não foi encontrado nas atividades lúdicas dos livros didáticos: papel 4 - permitir a atualização dos alunos. Enquanto alguns papéis são muito frequentes nessas atividades, outros aparecem em menor proporção. O papel 1 (oferecer motivação ao aluno, despertar seu interesse pelo ensino e proporcionar-lhe prazer) está presente em praticamente todas as atividades lúdicas dos livros examinados. Outros dois papéis com alta frequência são: papel 12 - possibilitar e facilitar a aprendizagem; e papel 11 - estabelecer conexões entre a realidade cotidiana dos alunos e os conteúdos curriculares). Os papéis que apresentaram menor ocorrência foram: papel 5 - possibilitar o planejamento e a execução de projetos); papel 7 - permitir uma maior exploração de linguagens artísticas; e papel 10 - explorar e desenvolver noções de mobilidade, medidas, proporções e relacionados. A distribuição de papéis acima relatada é apresentada a seguir no gráfico 1:

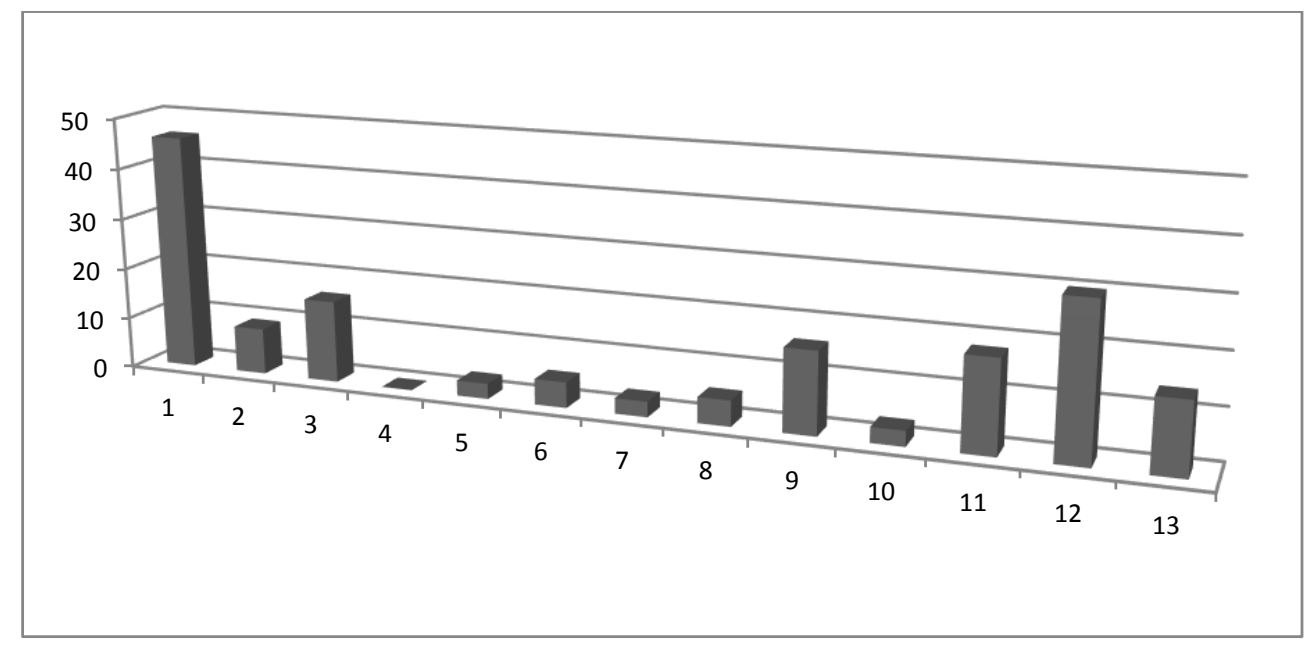

Gráfico 1 - Papéis das atividades lúdicas nos livros didáticos. Fonte: as autoras.

Verificamos uma convergência nas frequências de presença das imagens das atividades lúdicas nos currículos e nos livros didáticos quando analisados de forma geral. Tanto nos currículos quanto nas coleções didáticas investigadas, a imagem mais presente é a imagem 1 na qual a atividades lúdica é considerada como ação agente: aquela que promove o prazer, o entretenimento, a motivação, etc. Além da imagem 1, contatamos o mesmo perfil na distribuição das imagens 2 e 3 nos currículos e nos livros. Dessa maneira, percebe-se que existe uma recontextualização por parte dos livros didáticos a partir dos currículos sobre as atividades lúdicas em relação a sua função de agente, paciente e meio nos processos de ensino e aprendizagem.

Em relação aos papéis, não se observou essa correspondência de forma tão clara. Acreditamos que cada um dos papéis deve ser analisado separadamente com vistas a verificar se houve ou não a recontextualização. Acreditamos que não é possível generalizar os resultados 
integrando todos os papéis, portanto, não há como afirmar se houve ou não a recontextualização esperada.

Ressaltamos, porém que esse estudo se restringiu ao processo de recontextualização oficial do governo em relação as áreas de estudo e ao processo de recontextualização pedagógica dos autores e editoras selecionados em relação às orientações curriculares. Não podemos fazer inferências sobre a ação do professor diante da disponibilização ou não das atividades lúdicas nos livros didáticos, uma vez que esse não foi um elemento investigado na pesquisa. Assim, aspectos relacionados ao reconhecimento e ao entendimento do professor sobre tais atividades não integram o escopo desse estudo e se constituem como tópico em nossa agenda de pesquisa.

\section{DISCUSSÃO E CONCLUSÕES}

As atividades lúdicas se fazem presentes nos currículos e são consideradas por eles como importantes no processo de ensino e aprendizagem. Em alguns currículos como, por exemplo, nas DCNEB e no PNLD, essa importância é explicita. Em outros, como nos PCN, elas se fazem presentes de forma implícita ao longo do texto, pois o termo lúdico não é utilizado no documento. Chamou-nos a atenção a ausência do termo lúdico ou de qualquer outra palavra com algum tipo de relação às atividades lúdicas nos $C B C$ de Ciências de Minas Gerais. Comparando tal constatação com os resultados de Bertelli (2010), no qual a autora buscou identificar imagens e papéis dos museus nos currículos, podemos visualizar a grande lacuna existente nos $\mathrm{CBC}$ em relação a tais temas. A autora também não encontrou qualquer relação com os museus nos CBC de Ciências, expondo a grande deficiência desse currículo no que diz respeito a temas transversais e a utilização de espaços não-formais no ensino de Ciências.

A imagem de ação paciente, na qual as atividades lúdicas seriam realizadas por um processo, por exemplo, a descoberta do conhecimento pelo aluno e a imagem meio, uma ação que ocorre por meio de recursos como os jogos, vigoram nos currículos com a mesma frequência entre si, porém, cerca de 3,5 vezes menor com relação à imagem 1. Pensando nas afirmações de Carleto (2003) sobre as possibilidades escolares das atividades lúdicas que permitem o estabelecimento de relações pelas crianças que possibilitam a construção do conhecimento e levando em consideração a importância atribuída a tais atividades na aprendizagem, sobretudo em Ciências, conforme apontado por Moura (1993) observamos uma grande lacuna no referido documento.

Ao contrário do exposto, o PNLD mostrou uma elevada atribuição de valor a esses tipos de atividades em função da alta ocorrência do termo ou de palavras relacionadas ao longo do texto. $\mathrm{O}$ fato de o programa considerar a presença de atividades lúdicas nos livros como fator essencial à sua aprovação realça também tal importância. As atividades lúdicas presentes nos currículos possuem a imagem de ação que pode ser caracterizada como três diferentes tipos: agente, paciente e meio. A principal delas é a imagem agente, ou seja, são ações que promovem ou proporcionam o lazer, o prazer, a motivação e, consequentemente, facilitam a aprendizagem. A segunda e a terceira imagens (paciente e meio, respectivamente) apresentam-se nos currículos de forma equilibrada.

Podemos associar a imagem das atividades lúdicas como meio às afirmações de Macedo e Passos (2005) de que a utilização de jogos nas escolas tem como meta melhorar o desempenho escolar em termos de notas, produção e compreensão de conteúdos. Entre os currículos analisados, o PNLD é o que nos pareceu estar mais atento às potencialidades desse tipo de atividade e atribuir alto valor a ela.

Foi possível observar similaridades e singularidades nos papéis atribuídos às atividades lúdicas pelos diferentes currículos. Somente os PCN conferem às atividades com esse caráter os papéis de atualização dos alunos e de possibilitar o planejamento e execução de projetos. Apenas o PNLD garante às mesmas os papéis de transmitir conteúdos e de proporcionar a interação entre os alunos e entre os alunos e professores. Já ambos, PCN e PNLD, consideram que essas 
atividades têm o papel de desenvolver aspectos sociais, provocar um desafio de forma a estimular o estudante, permitindo e facilitando a aprendizagem. Os papéis concedidos pelas DCNEB se diferenciam bastante dos outros currículos. Esse documento afirma que as atividades lúdicas podem permitir maior exploração de linguagens artísticas, estabelecer conexões com o cotidiano dos alunos e qualificar a ação pedagógica. O referido currículo não apresentou nenhum papel em comum com o PNLD. Todavia, o papel de explorar e desenvolver noções de mobilidade, medidas e proporções é compartilhado entre as DCNEB e os PCN.

O único papel das atividades lúdicas presente em todos os currículos foi o de "oferecer motivação ao aluno, despertar seu interesse pelo ensino e proporcionar-lhe prazer" Acreditamos na relevância e necessidade do entusiasmo e motivação no processo de aprendizagem, porém, como apontado por Testa Braz da Silva, Mettrau e Barreto (2007), o papel do lúdico na relação ensino e aprendizagem de Ciências vai além de apenas proporcionar prazer no envolvimento dos estudantes.

A alta variedade de papéis concedidos às atividades lúdicas ilustra a ampla quantidade de significados associados ao termo lúdico, assim como apontado por Marcellino (1997), confirmando a imprecisão e o caráter abrangente do lúdico enquanto manifestação. A pouca similaridade e a alta disparidade de papéis encontrados nos diferentes currículos podem estar associadas aos órgãos que os produzem e suas concepções diferenciadas. Os PCN, por exemplo, um documento nacional, o mais antigo entre todos os analisados, apresentam papéis voltados à atualização dos alunos e realização de projetos, o que se afasta dos papéis das atividades lúdicas do PNLD.

Consideramos o número de 54 atividades lúdicas encontradas nas duas coleções de livros didáticos razoável, analisando as duas coleções em conjunto. Porém, há uma grande disparidade entre as duas obras, uma vez que a Coleção 1 apresenta um número muito maior de atividades dessa natureza em relação a Coleção 2. Na Coleção 1, Vontade de Saber Ciências, a maioria das atividades lúdicas se encontra no livro do aluno distribuída ao longo dos capítulos, enquanto na coleção 2, Ciência, Natureza e Cotidiano, todas as atividades lúdicas são apresentadas no manual do professor, apenas como sugestão de atividades a serem desenvolvidas pelo docente em sua prática diária. Observamos nesse contexto, que a Coleção 1 permite que tais atividades aconteçam com maior frequência na sala de aula que a Coleção 2. Por estar presente no livro do aluno em diferentes momentos e locais, ele terá diversas oportunidades de se deparar com essas ações, em contrapartida devido às atividades estarem contidas apenas no manual do professor podem ser consideradas como atividades extras, que devem ser realizadas em casos de sobra de tempo e, portanto, consideradas dispensáveis.

As três categorias de imagens de atividades lúdicas investigadas nos currículos foram encontradas nas atividades com essa essência nos livros didáticos selecionados. A imagem 1 (agente) está presente em quase todas as atividades lúdicas dos livros. A imagem 3 (meio) foi a segunda mais frequente nas obras, seguida pela imagem 2 (paciente), o que demonstra uma correspondência nas frequências de imagens entre os currículos e livros didáticos apenas em relação à imagem 1. Se analisarmos as duas coleções separadamente, constatamos a mesma distribuição acima descrita para a Coleção 1. Já a Coleção 2, não contém a imagem 1 em nenhuma de suas atividades, apenas as imagens 2 e 3 de forma equilibrada. Acreditamos que essa disparidade ocorre em função das atividades da Coleção 2 estarem baseadas em jogos. Dessa forma, podemos analisar o resultado em comum entre as duas coleções e percebemos uma convergência nas atribuições de imagem pelos currículos e livros em relação à imagem 1, o que poderia ser considerada uma evidência da recontextualização dos livros a partir dos currículos, em relação à imagem das atividades lúdicas.

Sobre os papéis atribuídos às atividades lúdicas, dos 13 identificados nos currículos, 12 estão presentes nas atividades lúdicas dos livros didáticos. O único papel não encontrado foi o de permitir a atualização dos alunos. Alguns papéis foram mais frequentes enquanto outros de 
forma esporádica. O papel 1 - oferecer motivação ao aluno, despertar seu interesse pelo ensino e proporcionar-lhe prazer -, presente em praticamente todas as atividades dos livros, também foi o único presente em todos os currículos analisados, o que nos indica um sinal de recontextualização. Outros dois papéis foram muito frequentes nas atividades dos livros tais como possibilitar e facilitar a aprendizagem e estabelecer conexões entre a realidade cotidiana dos alunos e os conteúdos curriculares. O primeiro está presente nos PCN e no PNLD os quais são de certa forma, guiados pelas DCNEB, e a alta frequência do mesmo nas atividades nos indica uma recontextualização. Já o terceiro papel mais frequente, sobre o estabelecimento de relações entre o cotidiano e o conteúdo escolar, está presente apenas nas DCNEB e, sendo este o currículo de maior abrangência, nos permite inferir o mesmo raciocínio.

Alguns papéis identificados nos currículos tiveram baixa frequência nas atividades lúdicas presentes nos livros e, por isso, associamos novamente às diferentes concepções de lúdico existentes como apontado por Marcellino (1997). Cada coleção pode abarcar vários autores e colaboradores que desenvolvem as atividades propostas de acordo com suas concepções e visões pessoais de lúdico. Porém, o fato de praticamente todos os papéis atribuídos aos currículos, com exceção de um, serem também encontrados nas atividades dos livros, nos permite entender que há um processo de recontextualização entre os livros e os documentos curriculares.

A partir dos resultados, podemos considerar que, de uma forma geral, os currículos vêm sendo claramente considerados no processo de produção dos livros didáticos. A convergência por nós verificada entre a principal imagem atribuída às atividades lúdicas, presente nos currículos e livros examinados, nos permite afirmar que a principal maneira pela qual as atividades lúdicas são compreendidas pelas orientações curriculares é também a principal forma como os livros de didáticos as compreendem. Assim, constatamos em relação à imagem que atribui a essas atividades o papel de agente, que há uma recontextualização dos livros didáticos com base nas orientações curriculares. Dessa maneira, de acordo com a teoria do dispositivo pedagógico de Bernstein (1996), há uma recontextualização do DPR (discurso pedagógico recontextualizador) em relação ao DPO (discurso pedagógico oficial).

A não correspondência entre a frequência das outras duas imagens, quando analisamos as coleções separadamente, ocorreram em função das diferentes localizações das atividades lúdicas nas duas obras. Esse fato não nos impede de afirmar que acontece o referido processo de recontextualização em relação às imagens que são atribuídas às atividades lúdicas. Apesar da presença de todos os papéis (exceto um) nos currículos e nos livros, não é possível inferir um processo de recontextualização entre eles e, dessa forma, achamos mais prudente analisá-los de maneira separada. Há um número muito maior de papéis do que de imagens envolvidos e, além disso, não conseguimos definir qual seria o critério pertinente para fazer tal afirmação.

As atividades lúdicas são propagadas pelos currículos como: ações que operam sob forma de agentes no processo de aprendizagem; ações que ocorrem por intermédio de um processo; e ações que acontecem com auxílio de um meio. Porém, a imagem destacadamente presente nos currículos é das atividades lúdicas como agente, ou seja, uma ação que irá promover o lazer, a motivação, o interesse e, como consequência, o aprendizado. Os currículos associam diversos papéis às atividades lúdicas reconhecendo suas variadas possibilidades. O único papel atribuído a essas atividades por todos os currículos - consequentemente o de maior destaque -, relacionase à motivação, ao interesse e ao prazer que o lúdico pode proporcionar ao aluno. As orientações curriculares associam também, de forma geral e constante, tais ações aos papéis de estimular o aluno por meio de desafios e reconhece as possibilidades de envolver questões sociais permitindo reflexão. Os currículos analisados, portanto, assumem as atividades lúdicas como possíveis facilitadoras da aprendizagem.

Os livros didáticos apresentam atividades lúdicas entremeadas em seu conteúdo e reconhecem sua importância. Porém, tais atividades são muitas vezes resumidas a charges e 
quadrinhos que são vistos como um auxílio para a compreensão do estudante, não explorando as possibilidades de aprimoramento da ação pedagógica. $\mathrm{O}$ fato de grande parte dessas práticas não qualificarem a ação pedagógica significa que, apesar de existirem as charges, os quadrinhos, as gincanas e os jogos, em sua maioria, não incentivam que as potencialidades lúdicas nelas contidas sejam exploradas, exercendo em determinadas circunstâncias a função de ilustração ou simples complemento de uma atividade ou da matéria. Além disso, a maioria das atividades lúdicas presente nos livros analisados se constitui de quadrinhos e charges, demonstrando a não inovação dos autores/editores, uma vez que há muito tempo esse tipo de estratégia já se faz presente nos materiais didáticos, o que evidencia uma recontextualização antiga pela pouca inovação presente.

Em algumas coleções, as atividades lúdicas são consideradas apenas como um complemento, pois se restringem aos manuais dos professores, tornando-os complementares, diminuindo as chances de realização destas em sala de aula. Dessa forma, apesar de estarem presentes nos livros, as atividades lúdicas ainda têm um baixo potencial de sua ludicidade verificado nessas práticas. Sobre a forma como os livros entendem tais ações, sobressai a imagem de ação agente, que pode promover uma série de possibilidades. As outras imagens verificadas nos currículos também são encontradas nas concepções sobre as atividades lúdicas nos livros didáticos, porém, em conformidade com os currículos, a imagem de ação com função de agente é prioritária.

Em função disso, podemos afirmar que os livros didáticos realizam a recontextualização sobre os currículos oficiais que orientam a educação pública no país e regem a produção dos livros didáticos. Em relação aos papéis atribuídos às atividades lúdicas pelos currículos e pelos livros didáticos, os dados encontrados na presente investigação não nos permitem afirmar que o processo de recontextualização está presente na produção das coleções. Entretanto, se analisarmos cada papel isoladamente, verificamos indícios do referido processo o que endossa nossa afirmação em relação aos papéis.

Acreditamos que as conclusões a que chegamos nessa pesquisa contribuem para as discussões relacionadas às possibilidades de utilização das atividades lúdicas nas escolas, sobretudo no ensino de Ciências bem como para a área de currículos focada nos processos de recontextualização entre o discurso oficial e o discurso pedagógico. Os resultados também abrem caminhos para novos questionamentos acerca dos motivos pelos quais apesar existirem nos livros didáticos, tais atividades não exploram o potencial lúdico inerente a elas limitando assim suas possibilidades enquanto facilitadoras da aprendizagem.

\section{REFERÊNCIAS}

BARDIN, L. Análise de conteúdo. $5^{\mathrm{a}}$ Edição. Lisboa: Edições 70, 2009.

BENJAMIM, W. Reflexões: Criança, o brinquedo, a educação. São Paulo, Summus, 1984.

BERNSTEIN, B. A estruturação do discurso pedagógico: classe, códigos e controle. Vozes: Petrópolis, 1996.

BERTELLI, M. Q. Identidades, Imagens e papéis museais nos discursos institucionais sobre a relação, museu-escola. Dissertação (mestrado em Educação) Faculdade de Educação, Universidade Federal de Minas Gerais, Belo Horizonte, 2010.

BRASIL, Ministério da Educação. Diretrizes Curriculares Nacionais para a Educação Básica. Brasília, 2013.

BRASIL, Secretaria de Educação Básica. Programa Nacional do Livro Didático. Brasília: MEC/SEB, 2014. 
BRASIL, Secretaria de Educação Fundamental. Parâmetros Curriculares Nacionais para $5^{\mathbf{a}}$ a 8aㅗ séries. Brasília: MEC/SEF, 1998.

BROUGÈRE, G. Jogo e educação. Porto Alegre: Artes Médicas, 1998.

CALADO, S.; NEVES, I. P. Currículo e manuais escolares em contexto de flexibilidade curricular - Estudo de processos de recontextualização. Revista Portuguesa de Educação, 25(1), p. 53-93, 2012.

CARLETO, E. A. O lúdico como estratégia de aprendizagem. Olhares \& Trilhas (UFU), v. 4, p. 97-104, 2003.

FRIEDMANN, A. Brincar: crescer e aprender - o resgate do jogo infantil. São Paulo: Moderna, 1996.

HUIZINGA, J. Homo Ludens: o jogo como elemento da cultura. São Paulo: Perspectiva/ Edusp, 1971.

KISHIMOTO, T. M. (Org.). Jogo, brinquedo, brincadeira e educação. São Paulo: Cortez, 1999.

LOPES, A. C. Política de currículo: recontextualização e hibridismo. Currículo sem Fronteiras, v. 5, n. 2, p. 50-64, 2005. Disponível em: <www.curriculosemfronteiras.org>. Acesso em 22 abril. 2017.

MACEDO, L. A dimensão lúdica nos processos de aprendizagem. FOLHA Educação, v. 2o, p. 6-7, março/abril 2003.

MACEDO, L.; PASSOS, N. C. Os jogos e o lúdico na aprendizagem escolar. 1. ed. Porto Alegre: ARTMED, 2005.

MARCELLINO, N. C. Pedagogia da animação. São Paulo. Papirus, 1997

MINAS GERAIS, Secretaria de Estado de Educação. Conteúdos Básicos Curriculares, Ciências, Ensino Fundamental. SEE MG/ 2006.

MOURA, D. G. O elemento lúdico no ensino de física. Tese (Doutorado em Educação) Programa de Pós-Graduação em Educação, Universidade de São Paulo, São Paulo, 1993.

POZO, J. I.; CRESPO, M. A. G. A aprendizagem e o ensino de Ciências: do conhecimento cotidiano ao conhecimento científico. $5^{\mathrm{a}}$ ed. Porto Alegre: Artmed, 2009.

SILVA, T. T. Documentos de identidade: uma introdução às teorias do currículo. Belo Horizonte: Autêntica, 1999.

TESTA BRAZ DA SILVA, A. M.; METTRAU, M. B.; BARRETO, M. S. L. O lúdico no processo de ensinoaprendizagem das Ciências. Revista Brasileira de Estudos Pedagógicos, v. 88, p. 1-10, 2007.

VOLPATO, G. Jogo e brinquedo: reflexões a partir da teoria crítica. Educ. Soc., Campinas, v. 23, n. 81, p. 217-226, dez. 2002. Disponível em: <http://www.cedes.unicamp.br>. Acesso em 22 abr. 2017. 
Bárbara Elisa Santos Carvalho Luz: Mestra e doutoranda pelo Programa de Pós-Graduação em Educação da Universidade Federal de Minas Gerais (UFMG). Licenciada em Ciências Biológicas (UFMG). Atua como professora da Educação Básica na região metropolitana de Belo Horizonte/MG.

E-mail: barbaraecarvalho@hotmail.com

Mônica da Silva Gallon: Mestra e doutoranda pelo Programa de Pós-Graduação em Educação em Ciências e Matemática (PUCRS). Graduada em Ciências Biológicas (UNISINOS) e Pedagogia (UNINTER). Professora na rede municipal de Canoas/RS.

E-mail: monica.gallo@gmail.com

Silvania Sousa do Nascimento: Graduada em Física (UFMG), Mestre em Ensino de Ciências (IFUSP) e doutora em Educação (Universidade Paris VI). Professora titular do Departamento de Métodos e Técnicas de Ensino e do Programa de Pós-Graduação em Educação da Faculdade de Educação da Universidade Federal de Minas Gerais (UFMG).

E-mail:silvania.nascimento@gmail.com 